\title{
An Evaluation of the Frequency and Severity of Erectile Dysfunction in Hypertensive Married Men Compared with Normotensive Married Men
}

\author{
Kabirul Hasan Bin Rakib", *, Afroja Alam², Md. Atikur Rahman ${ }^{3}$, Nazim Al Azad ${ }^{4}$, \\ Akm Habibullah Bahar ${ }^{5}$, Nazmul Hoque Munna ${ }^{6}$, Rabeya Bosri ${ }^{7}$, Shaheen Lipika Quayum ${ }^{8}$, \\ Md. Abul Kalam Azad ${ }^{9}$ \\ ${ }^{1}$ Department of Medicine, Mugda Medical College Hospital, Mugda, Dhaka, Bangladesh \\ ${ }^{2}$ Department of Medicine, Bangabandhu Sheikh Mujib Medical University (BSMMU), Dhaka, Bangladesh \\ ${ }^{3}$ OSD-Directorate General of Health Services (DGHS), Mohakhali, Dhaka, Bangladesh \\ ${ }^{4}$ Department of Internal Medicine, Mugda Medical College Hospital, Mugda, Dhaka, Bangladesh \\ ${ }^{5}$ Department of Medicine, 250 Bedded General Hospital, Tangail, Bangladesh \\ ${ }^{6}$ Department of Neurology, Mugda Medical College Hospital, Mugda, Dhaka, Bangladesh \\ ${ }^{7}$ Department of Gynae \& Obs., Mugda Medical College Hospital, Dhaka, Bangladesh \\ ${ }^{8}$ Department of Pharmacology, Popular Medical College, Dhaka, Bangladesh \\ ${ }^{9}$ Department of Internal Medicine, Bangabandhu Sheikh Mujib Medical University (BSMMU), Dhaka, Bangladesh
}

Email address:

khbrakib@gmail.com (K. H. B. Rakib)

${ }^{*}$ Corresponding author

\section{To cite this article:}

Kabirul Hasan Bin Rakib, Afroja Alam, Md. Atikur Rahman, Nazim Al Azad, Akm Habibullah Bahar, Nazmul Hoque Munna, Rabeya Bosri, Shaheen Lipika Quayum, Md. Abul Kalam Azad. An Evaluation of the Frequency and Severity of Erectile Dysfunction in Hypertensive Married Men Compared with Normotensive Married Men. Cardiology and Cardiovascular Research. Vol. 4, No. 3, 2020, pp. 85-91. doi: 10.11648/j.ccr.20200403.12

Received: April 22, 2020; Accepted: May 21, 2020; Published: June 9, 2020

\begin{abstract}
Background: Erectile dysfunction (ED) exerts a major burden on the quality of life of the patients and their sexual partners. It has been identified as an independent risk factor for cardiovascular disease. Hypertension is a wellestablished risk factor for ED. Both hypertension and erectile dysfunction has age dependent relationship. Objective: To evaluate the frequency and severity of erectile dysfunction in hypertensive married men compared with normotensive married men of similar demographic characteristics attending a tertiary care hospital of Bangladesh during the period from June 2017 to March, 2018. Methodology: This cross-sectional comparative study includes 75 hypertensive and 75 normotensive young and middle-aged married men (31-59 years) those visited our outpatient clinic. From them, 75 patients had hypertension and 75 were normotensive. Erectile dysfunction was evaluated with pre validated Bengali version of the International Index of Erectile Function (IIEF-5) questionnaire. Results: Erectile dysfunction (ED) was found in $61.3 \%$ of patients with hypertension compared with $37.3 \%$ of normotensive subjects. ED is more common and more severe among hypertensive patients than normotensive counterparts. Hypertension duration, hypertension severity and age were found positively correlated with erectile dysfunction. Taking regular medication and control of BP gave positive influence upon erectile status. No association was found between ED and smoking but a weak negative correlation of increased body mass index (BMI) and decreased ED was found in both hypertensive and normotensive group. Conclusion: Hypertensive patients present with erectile dysfunction more frequently than age matched normotensive individuals. As erectile dysfunction is a matter of embarrassment, doctors should be motivated to discuss such issue. Control of blood pressure seems to confer good influence upon the prevalence of erectile status. We need further studies to authenticate such observation and to unveil other risk factors of ED in our country and to go for appropriate management.
\end{abstract}


Keywords: Erectile Dysfunction (ED), Cardiovascular, Hypertension, Body Mass Index (BMI)

\section{Introduction}

Erectile dysfunction is a common clinical problem. It interferes with a man's self-esteem, interpersonal relationships and sense of wellbeing. ED affects the quality of life of both patients and their sexual partners. Essential hypertension is widely accepted as a risk factor for erectile dysfunction. Erectile dysfunction is currently considered to be due to atherosclerotic lesions of the penile arteries. It is considered to be a forerunner of Ischemic heart disease and a risk factor of IHD along with Hypertension and others. In Bangladesh life expectancy is increasing day by day. Beta blockers (i.e. bisoprolol, atenolol, carvedilol and metoprolol), which were practiced for the treatment of hypertension patients in coronary artery disease patients expressed ED in $13 \%$ to $28 \%$ of patients but nebivolol was found to have less (10\%) impact upon ED [1]. Some studies revealed calcium channel blockers have low association with ED [2]. The incidence of erectile dysfunction is minimal with ACE inhibitors. Bate et al [3] revealed ED for the angiotensin converting enzyme (ACE) inhibitors was less than 1\%. Some data propose that sexual function and ED may improve through treatment with Angiotensin receptor blockers (ARB) [4]. The favorable effects of angiotensin II antagonists (AIIAs) on sexual function may be related to their ability to block angiotensin II (ANG II), which has been shown to terminate spontaneous erections when administered exogenously in an experimental model of penile function [5]. According to the World Health Organization WHO (2017) [6], life expectancy in Bangladesh is 71.1 years in male and 74.4 years in female and the total life expectancy is 72.7 years. As Hypertension and sexual dysfunction has agedependent relationship, an outbreak in their prevalence is likely to take place over the next decades. Both duration and severity of hypertension have significant role upon erectile function. Erectile dysfunction is more common and severe in patients who have hypertension for longer duration ( $>5-6$ years) [7]. Similarly, patients with severe hypertension suffer from severe ED [8]. The effects of erectile dysfunction are profound. It interferes with a man's confidence and sense of wellbeing [9]. Erectile dysfunction and cardiovascular disease are thought to have some shared pathways on the basis of animal and human models [10]. It can be considered as a symptom of vascular endothelial damage [11]. Endothelial dysfunction is thought to be the common denominator in the pathophysiology of both CVD and ED [12]. The "artery-size hypothesis" of Montorsi et al [13] suggests that on an average, ED occurs three (3) years prior to a subsequent cardiovascular event. Erectile dysfunction has been identified as an independent risk factor for cardiovascular disease. The hazard ratio is 1.45 which is equal or greater compared to traditional risk factors like hyperlipidemia, smoking, positive family history [14]. But more than $70 \%$ of erectile dysfunction remains undiagnosed [15]. The physicians' reluctance to ask about such abnormalities is the main cause of it. Inadequate training and misperceptions of medical practitioners may also contribute. ED is almost ignored by the Bangladeshi researchers. But it can be easily detected by having male patients' complete standardized questionnaires IIEF -5. Rosen et al [16] which consists of items $1,2,3,4,5$ and 15 from the full-scale IIEF15; a sum score of 24 or less indicates the presence of ED. A study conducted in 2015 described ED to be very high (53.98\%) in Bangladeshi diabetic men. But there is no study in Bangladesh among hypertensive population addressing this important issue.

\section{Objectives}

a) General objective:

1. To compare the frequency and severity of erectile dysfunction among hypertensive and normotensive married men attending a tertiary care hospital of Bangladesh.

b) Specific Objectives:

1. To find out the frequency of erectile dysfunction among hypertensive and normotensive married men attending in a tertiary care hospital of Bangladesh.

2. To find out the severity of erectile dysfunction among hypertensive and normotensive married men attending in a tertiary care hospital of Bangladesh.

\section{Methodology and Materials}

It was a cross sectional comparative study. The study was done in the Department of Internal Medicine, Bangabandhu Sheikh Mujib Medical University, Shahbag, Dhaka. The study was done from date of IRB approval (June 2017 to March, 2018). The protocol was approved by the Institutional Review Board (IRB) of Bangabandhu Sheikh Mujib Medical University (BSMMU) Dhaka. A total of 150 patients were selected as a study population. Purposive sampling was applied to collect the sample as per inclusion and exclusion criteria. The study was conducted in accordance with the principles of the Helsinki declaration after approval by institutional review board. Subjects were taken when they gave informed consent, and the procedures were followed in accordance with institutional guidelines. An informed written consent was obtained; procedure was followed according to institutional guidelines. Secondary hypertension was excluded by history, clinical examination and documented laboratory investigations. A data collection sheet containing details of patient's demographic data along with detailed information regarding hypertension severity, hypertension duration, medication etc. Erectile dysfunction was evaluated by a standardized questionnaire. After collecting the data, it was checked and rechecked for omission, inconsistencies and 
improbabilities. Data analysis was performed by Statistical Package for Social Science (SPSS), version-22. The frequency and severity of erectile dysfunction and other categorical variables were reported as proportion with $95 \%$ confidence interval. The categorical data were compared by chi-square test followed by logistic regression analysis as a significant level of $0.05 \%$. Logistic regression analysis was employed to determine the factors related to erectile dysfunction.

1. Inclusion Criteria

a) Age of 20 years to 59 years

b) Gender: male

c) Married state and active sexual relationship with wife or wives for at least the past 6 months

d) Known hypertensive for at least 6 months

e) Agree to participate and sign the informed consent ( irrespective of medication and status)

f) Capable to answer a self-applied questionnaire

2. Exclusion Criteria

a) Any known disease of the male genitalia

b) Known secondary hypertension

c) Known diabetes mellitus

d) A history of substance or drug abuse

\section{Results}

Analysis was done with the data of 150 cases. Out of the total 150 cases 75 were hypertensive and 75 were normotensive. The respondents were further sub grouped into an age matched manner. Though selection criteria included 20 to 59 years of age group; none was found in the range of 20 to 29 years age. So the study subjects were subdivided into $30-39$ years, 40- 49 years and $50-59$ years. The predominant respondent age group was 40 to 49 years which included 42 in normotensive group and 42 in hypertensive group. The age range of the normotensive was 33-55 years in the study population and the mean age of them was $(42.65 \pm 5.53)$ years. On the other hand, the age range of the hypertensive was 30 - 59 years. Mean age was (44 \pm 7.4 ) years. The unpaired t-test showed no significant difference between two mean age group. In both the hypertensive and normotensive study subjects, most of the respondents came from rural area which included $81.3 \%$ in normotensive population and $70 \%$ in hypertensive population. Few subjects $(8 \%)$ were illiterate in both normotensive and hypertensive group. Most of the participants (32\%) in normotensive group completed primary education and in the hypertensive group most $(28 \%)$ of the respondents were graduate. In respect of occupation it was found that large number of subjects was private service holder which included $57.3 \%$ and $49.3 \%$ in normotensive and hypertensive group respectively. Most of the participants were from lower socioeconomic background. They were $68 \%$ in normotensive group and $66.7 \%$ in hypertensive group. Regarding personal habits $41.3 \%$ among the normotensive and $38.7 \%$ among the hypertensive were indulging in smoking and tobacco leaf chewing. Table 1 shows the association of BMI with blood pressure in hypertensive and normotensive population. Among 75 normotensive study subjects $28(37.3 \%)$ persons had erectile dysfunction (ED) and the rest $47(62.7 \%)$ persons had not ED. Concomitantly among the 75 hypertensive sample 46 $(61.3 \%)$ had ED and the remaining 29 (38.7\%) didn't have ED (Table 2). The study subjects were categorized on the basis of their International Index of Erectile Function (IIEF5 ) score. Nobody was found in the range of severe ED (IIEF5 score 0-6) both in hypertensive and normotensive group. In the moderate to severe range (IIEF-5 score 7-12) hypertensive is $5(6.7 \%)$ and the normotensive is $0(0 \%)$ out of 75 in each group. In the mild to moderate categories (IIEF5 score 13-18) the hypertensive study subjects have more ED. The mild group (IIEF -5 score 19-24) were difference in between the groups [13 (17.3\%) in normotensive population and $14(18.7 \%)$ in hypertensive population. The normotensives had significantly much more number of subjects with no ED in comparison to hypertensive (47 vs 29) (Table 3). Forty-nine (49) hypertensive persons were taking different antihypertensive medications. Out of them thirtythree (33) subjects were on regular medications 16 (48.5\%) of which were suffering from ED and 17 (51.5\%) were not. Of the 16 known hypertensive men who were taking medicines in an irregular manner $14(87.5 \%)$ had ED and only $2(12.5 \%)$ had not (Table 4). Subjects who had controlled BP had highly significantly less ED than those of uncontrolled BP (Table 5). The study population was further analyzed by making some subgroups on the basis of age at a range of 30 -39 years, $40-49$ years, and 50-59 years to find out any correlation of age. Both numerically and statistically no association was found in the age group of 30- 39 and in 40 -49 years of age group. But in the age group of 50 to 59 years the variation was significant (Table 6). The normotensive men aged 50-59 years didn't found to be associated with significant risk factors for ED (Table 7).

Table 1. Demographic characteristics of the study subjects $(n=150)$.

\begin{tabular}{lll}
\hline Demographic variables & $\begin{array}{l}\text { Normotensive } \\
\text { (n=75) No. }(\%)\end{array}$ & $\begin{array}{l}\text { Hypertensive } \\
(\mathbf{n = 7 5}) \mathbf{N o .}(\mathbf{\%})\end{array}$ \\
\hline Age group (in years) & $20(26.7)$ & $16(21.3)$ \\
$30-39$ & $42(56.0)$ & $42(56.0)$ \\
$40-49$ & $13(17.3)$ & $17(22.7)$ \\
$50-59$ & $75(100.0)$ & $75(100.0)$ \\
Total & $42.65 \pm 5.53$ & $44.0 \pm 7.4$ \\
Mean \pm SD & $(33-55)$ yrs. & $(30-59) \mathrm{yrs}$. \\
Range & & \\
Residence & $14(18.7)$ & $22(29.3)$ \\
Urban & $61(81.3)$ & $53(70.0)$ \\
Rural & & $1(1.3 \%)$ \\
Occupational status & $1(1.3 \%)$ & $4(5.3 \%)$ \\
Unemployed/Dependent & $2(2.7 \%)$ & $17(22.7 \%)$ \\
Farmer & $17(22.7 \%)$ & $6(8.0 \%)$ \\
Businessman & $3(4.0 \%)$ & $37(49.3 \%)$ \\
Government jobs & $43(57.3 \%)$ & $7(9.3 \%)$ \\
Private service & $6(8.0 \%)$ & $4(5.0 \%)$ \\
Workers & $3(4.0 \%)$ & \\
Other & & \\
Level of education & & \\
\hline
\end{tabular}




\begin{tabular}{|c|c|c|}
\hline Demographic variables & $\begin{array}{l}\text { Normotensive } \\
(\mathrm{n}=75) \text { No. }(\%)\end{array}$ & $\begin{array}{l}\text { Hypertensive } \\
(\mathrm{n}=75) \text { No. }(\%)\end{array}$ \\
\hline Illiterate & $6(8.0 \%)$ & $6(8.0 \%)$ \\
\hline Primary & $24(32.0 \%)$ & $18(24.0 \%)$ \\
\hline Secondary & $14(18.7 \%)$ & $11(14.7 \%)$ \\
\hline Higher secondary & $11(14.7 \%)$ & $12(16.0 \%)$ \\
\hline Graduate & $12(16.0 \%)$ & $21(28.0 \%)$ \\
\hline Post Graduate & $8(10.7 \%)$ & $7(9.3 \%)$ \\
\hline $\begin{array}{l}\text { Lower income group }(<5000 \\
\text { Tk/month) }\end{array}$ & $51(68.0 \%)$ & $50(66.7 \%)$ \\
\hline $\begin{array}{l}\text { Middle income group (5000- } \\
50000 \mathrm{Tk} / \mathrm{month})\end{array}$ & $17(22.7)$ & $14(18.7 \%)$ \\
\hline $\begin{array}{l}\text { Upper income group (>50000 } \\
\text { Tk/month) }\end{array}$ & $7(9.3 \%)$ & $14(18.7 \%)$ \\
\hline \multicolumn{3}{|c|}{ Smoking and tobacco leaf chewing } \\
\hline Yes & $31(41.3 \%)$ & $29(38.7 \%)$ \\
\hline No & $44(58.7 \%)$ & $46(61.3 \%)$ \\
\hline Underweight $(<18.5)$ & $2(2.7 \%)$ & $1(1.3 \%)$ \\
\hline Normal weight (18.5-24.99) & $59(78.7 \%)$ & $48(64.0 \%)$ \\
\hline Overweight (25-29.99) & $12(16.0 \%)$ & $24(32.0 \%)$ \\
\hline Obese $(>30)$ & $2(2.7 \%)$ & $2(2.7 \%)$ \\
\hline
\end{tabular}

Data were expressed as frequency and percentage. Chisquare test was done to see the association of personal habits between groups.
Table 2. Presence of erectile dysfunction among hypertensive and normotensive individuals $(n=150)$.

\begin{tabular}{llll}
\hline \multirow{2}{*}{ Status of blood pressure } & \multirow{2}{*}{ N } & \multicolumn{2}{l}{ Status of ED } \\
\cline { 3 - 4 } & & Present & Absent \\
\hline Normotensive $(\mathrm{n}=75)$ No. $(\%)$ & 75 & $28(37.3 \%)$ & $47(62.7 \%)$ \\
Hypertensive $(\mathrm{n}=75)$ No. $(\%)$ & 75 & $46(61.3 \%)$ & $29(38.7 \%)$ \\
\hline
\end{tabular}

Data were expressed as frequency and percentage. Chisquare test was done to see the association of personal habits between groups.

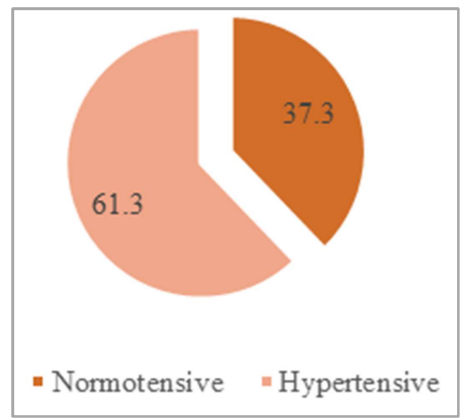

Figure 1. Pie chart showing the presence of erectile dysfunction among hypertensive and normotensive study subjects. $(n=150)$.

Table 3. Distribution of the study subjects according to erectile dysfunction severity ( $n=150)$.

\begin{tabular}{llllll}
\hline Severity of ED (range of IIEF-5 score) & $\mathbf{N}$ & Moderate to severe (7-12) & Mild to moderate (13-18) & Mild (19-24) & No (25-30) \\
\hline Normotensive & 75 & $0(0.0 \%)$ & $15(20.0 \%)$ & $13(17.3 \%)$ & $47(62.7 \%)$ \\
Hypertensive & 75 & $5(6.7 \%)$ & $27(36.0 \%)$ & $14(18.7 \%)$ & $29(38.7 \%)$ \\
\hline
\end{tabular}

Data were expressed as frequency and percentage; Chi-square test was done to see the association of severity of erectile dysfunction between groups

Table 4. Effect of regular of medication on erectile dysfunction ( $n=49)$.

\begin{tabular}{llll}
\hline $\begin{array}{l}\text { Status of taking medication among } \\
\text { hypertensive subjects }\end{array}$ & $\mathbf{N}$ & Presence of ED & Absent (n=75) No. (\%) \\
\cline { 2 - 4 } & 33 & Present (n=75) No. (\%) & $47(62.7 \%)$ \\
Regular & 16 & $46(61.3 \%)$ & $29(38.7 \%)$ \\
Irregular & 49 & $30(57.1 \%)$ & $19(42.9 \%)$ \\
\hline
\end{tabular}

Data were expressed as frequency and percentage. Fisher Exact test was done to see the association of severity of erectile dysfunction with status of taking medication regularly or irregularly.

Table 5. Association of blood pressure control with erectile dysfunction (ED) status ( $n=75$ ).

\begin{tabular}{llll}
\hline \multirow{2}{*}{ Control of BP } & N & Presence of ED & \\
\cline { 2 - 4 } & & Present (n=46) No. (\%) & Absent (n=29) No. (\%) \\
\hline Controlled & 49 & $24(49 \%)$ & $25(51 \%)$ \\
Uncontrolled & 26 & $22(84.6 \%)$ & $4(15.4 \%)$ \\
Total & 75 & $46(100 \%)$ & $29(100.0 \%)$ \\
\hline
\end{tabular}

Data were expressed as frequency and percentage. Chi-square test done to see the association of severity of erectile dysfunction with status of taking medication.

Table 6. Association of severity of erectile dysfunction (ED) with different age group. $(n=75)$.

\begin{tabular}{llll}
\hline \multirow{2}{*}{ Age group Severity of ED (IIEF-5 score) (in year) } & Group \\
\cline { 2 - 3 } & Moderate to severe (7-12) & Normotensive No. (\%) & Hypertensive No. (\%) \\
\hline \multirow{3}{*}{$30-39$} & Mild to moderate $(13-18)$ & $3(15.0 \%)$ & $1(6.3 \%)$ \\
& Mild (19-24) & $5(25.0 \%)$ & $4(25.0 \%)$ \\
& No (25-30) & $12(60.0 \%)$ & $6(37.5 \%)$ \\
& Total & $20(100.0 \%)$ & $5(31.5 \%)$ \\
\hline
\end{tabular}




\begin{tabular}{llll}
\hline \multirow{2}{*}{ Age group Severity of ED (IIEF-5 score) (in year) } & Group & Hypertensive No. (\%) \\
\cline { 3 - 4 } & Moderate to severe (7-12) & Normotensive No. (\%) & $2(4.8 \%)$ \\
$40-49$ & Mild to moderate (13-18) & $0(0.0 \%)$ & $13(30.9 \%)$ \\
& Mild (19-24) & $8(19.0 \%)$ & $7(16.7 \%)$ \\
& No (25-30) & $8(19.0 \%)$ & $20(47.6 \%)$ \\
& Total & $26(61.9 \%)$ & $42(100.0 \%)$ \\
$50-59$ & Moderate to severe (7-12) & $42(100.0 \%)$ & $3(17.6 \%)$ \\
& Mild to moderate (13-18) & $0(0.0 \%)$ & $8(47.1 \%)$ \\
& Mild (19-24) & $4(30.8 \%)$ & $2(11.8 \%)$ \\
& No (25-30) & $0(0.0 \%)$ & $4(23.5 \%)$ \\
& Total & $9(69.2 \%)$ & $17(100.0 \%)$ \\
\hline
\end{tabular}

Data were expressed as frequency and percentage. Chi-square test done to see the association of severity of erectile dysfunction with different age group.

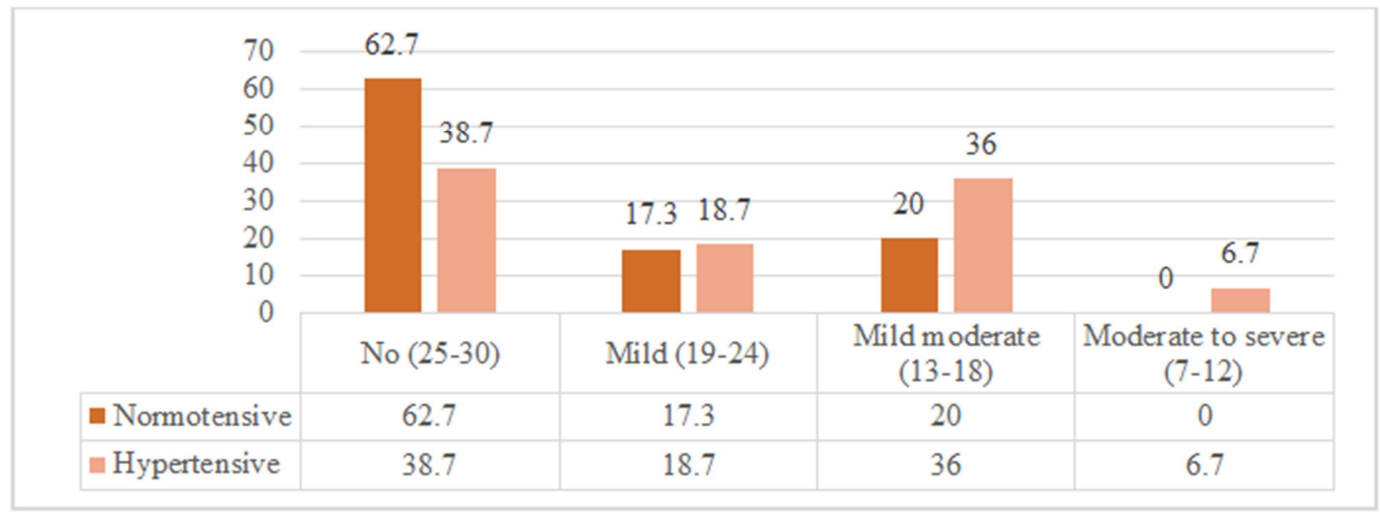

Figure 2. Bar diagram showing the severity of erectile dysfunction (ED) according to blood pressure. ( $n=150)$.

\section{Discussion}

It was observed that erectile dysfunction was more prevalent in patients with hypertension compared with agematched normotensive individuals. The study indicated that; the severity of erectile dysfunction was greater in hypertensive than in age matched normotensive individuals. Anti-hypertensive drug administration and life style modification through dieting and other measure was positively related to erectile function. Controlling of BP gave a good outcome on erectile function. Taking regular antihypertensive medication was found to be a good practice and had positive influence upon the erectile function. Erectile dysfunction was influenced by the severity of hypertension. Longer duration of hypertension resulted in increased frequency and severity of erectile dysfunction. Age was an important determinant of erectile function. Hypertension along with age potentiated the risk of ED mainly after the age of 50 years. No significant correlation was found in hypertensive participants with their habit of smoking and/ or tobacco leaf chewing but a weak negative correlation was found with increased BMI and decreased erectile status in both hypertensive and normotensive population. The study revealed the frequency of ED in patients with hypertension alone $61.3 \%$, while in normotensive men $37.3 \%$. The subjects who were interviewed were mostly unaware that they might have ED. The IIEF-5 questionnaire Bengali version elicited the ED and the range of severities reported by them. The frequency of ED in this study among hypertensive married men was similar to that found in studies carried out by Burchardt, M et. al [17] in the USA, which showed the prevalence of ED to be $68.3 \%$ among hypertensive outpatients. However, studies by Jensen, J et. al [18] found a lower prevalence of ED, 35.2\% and $26.7 \%$ respectively, among hypertensive patients. A multicenter Egyptian National study demonstrated that the prevalence of ED was $43.2 \%$ in the Egyptian male population [19]. Although hypertension is related to erectile dysfunction, the onset of erectile dysfunction is related to the initiation of antihypertensive therapy [20]. As many as $25 \%$ of cases of erectile dysfunction are related to medication side effects, with antihypertensive drugs being the most concerned class [21] However, scientific data that links antihypertensive medication to erectile dysfunction in placebo- controlled trials is very limited [22] and it is not proven [23]. This study evidenced that patients who take antihypertensive medication exhibited less erectile dysfunction. While patients who didn't take any medication had more ED. Due to certain constrains there was no option to determine the role of individual antihypertensive drug or modality of treatment of HTN, upon ED here in this study. Moreover, the use of specific antihypertensive medicine or any combination antihypertensive taken by the study subjects was not known; as it was beyond the scope of this article. But it was marked that patient who took antihypertensive medication properly had low ED than those who were not taking. It is confirmed that ED is highly correlated with vascular disease. 
Hypertension, dyslipidemia, diabetes, and smoking predict the risk of developing vascular disease and erectile dysfunction [24]. The studied hypertensive participants with smoking and tobacco leaf chewing habits had no significant association. Smoking and/or tobacco leaf chewing was explored among the study subjects who didn't have significant variation between the normotensive and hypertensive group. There are many recent observational studies on smoking and risk of erectile dysfunction (ED). The evidence available on the association between smoking and ED is inconclusive [25]. A literature review concluded that smokers are 1.5 times more likely to suffer from erectile dysfunction than non-smokers [26]. In the baseline sample of the MMAS, smoking was not independently associated with erectile dysfunction, but it exacerbated the effects of heart disease, high blood pressure and antihypertensive medication [27]. Smoking was not associated with ED in the whole follow-up sample. [28] The association between smoking and / or tobacco leaf chewing with ED was not analyzed in this study. Obesity has been shown to increase the prevalence of ED in some studies [29-31] Obese patients also have an increased prevalence of vascular risk factors [32]. In the MMAS, obesity was an independent predictor of ED [33]. Multiple cross-sectional studies have shown that overweight (body mass index [BMI] 25 to $30 \mathrm{~kg} / \mathrm{m}^{2}$ ) and obese $\left(\right.$ BMI $\left.>30 \mathrm{~kg} / \mathrm{m}^{2}\right)$ men have an incremental increase in the risk of ED with the relative risk ranging from 1.5 to 3.0fold]34]. A randomization was done in a prospective study by Esposito et al upon 55 men with ED to healthy behaviors (caloric reduction and consistent exercise) vs. control. After a follow- up of two years, the treatment arm averaged 15 $\mathrm{kg}$ of weight loss with $31 \%$ regaining normal erectile function compared to $2 \%$ in the control arm. Obesity in itself may not be a direct risk factor, but can induce vasculogenic impotence through increasing risk of chronic diseases including diabetes, hypertension, heart disease and hyperlipidemia. A weak negative correlation of increased BMI with decreased erectile functionality was found in both Hypertensive and normotensive study subjects.

\section{Limitations of the Study}

Being a hospital-based study, finding of this study are not generalized. It didn't include all the targeted population. Certainly, it cannot reflect the actual scenario regarding the frequency and severity of ED among hypertensive and normotensive population of the whole country.

\section{Conclusion and Recommendations}

The study indicated that the severity of erectile dysfunction was greater in hypertensive individuals than in age matched normotensive individuals. Anti-hypertensive drug administration and life style modification through dieting and other measure was positively related to erectile function. Controlling of BP gave a good outcome on erectile function. Taking regular anti-hypertensive medication was found to be a good practice and had positive influence upon the erectile function. Presence of ED in hypertensive patients should not be recognized instantly to any antihypertensive medications. All other causes of ED should be considered.

\section{References}

[1] Cordero, A., Bertomeu Martínez, V., Mazón, P., Fácila, L., Bertomeu口González, V., Conthe, P., et al 2010. Erectile dysfunction in high risk hypertensive patients treated with beta blockade agents. Cardiovascular Therapeutics 28 (1), pp. 15-22.

[2] Caro, J. L. L., Vidal, J. V. L., Roca, M. A., Bravo, C. P., Vicente, J. A., Ferrario, C. M. et al., 2001. Sexual dysfunction in hypertensive patients treated with losartan. The American Journal of the Medical Sciences 321 (5), pp. 336-41.

[3] Bate, A., Lindquist, M., Edwards, I. R., Olsson, S., Orre, R., Lansner, A. and De Freitas, R. M., 1998. A Bayesian neural network method for adverse drug reaction signal generation. European Journal of Clinical Pharmacology 54 (4), pp. 315-21.

[4] Della, CA, Pfiffner, D, Meier, B and Hess OM., 2003 Sexual activity in hypertensive men. Journal of human Hypertension. 17 (8), pp. 515-21.

[5] Kifor, I., Williams, G. H., Vickers, M. A., Sullivan, M. P., Jodbert, P. and Dluhy, R. G., 1997. Tissue angiotensin II as a modulator of erectile function. I. Angiotensin peptide content, secretion and effects in the corpus cavernosum. The Journal of Urology 157 (5), pp. 1920-25.

[6] WHO. 2017. Life expectancy report of Bangladesh. 2017, Geneva. World Health Organization, Available from www. world life expectancy.com/country - healthprofile/Bangladesh.

[7] Doumas, M., Tsakiris, A., Douma, S., Grigorakis, A., Papadopoulos, A., Hounta, A., Tsiodras, S., Dimitriou, D. and Giamarellou, H., 2006. Factors affecting the increased prevalence of erectile dysfunction in Greek hypertensive compared with normotensive subjects. Journal of Andrology 27 (3), pp. 469-77.

[8] Doumas, M. and Douma, S., 2006. The effect of antihypertensive drugs on erectile function: a proposed management algorithm. The Journal of Clinical Hypertension 8(5), pp. 359-63.

[9] Laumann, E. O., Paik, A. and Rosen, R. C., 1999. Lecture 6: the epidemiology of erectile dysfunction: results from the National Health and Social Life Survey. International Journal of Impotence Research 11 ( suppl 1), pp. S60-S64.

[10] Sullivan, M. E., Keoghane, S. R. and Miller, M. A. W., 2001. Vascular risk factors and erectile dysfunction. British Journal of Urology International, 87 (9), pp. 838-45.

[11] Sasayama, S., Ishii, N., Ishikura, F., Kamijima, G., Ogawa, S., Kanmatsuse, K., Kimoto, Y., Sakuma, I., Nonogi, H., Matsumori, A. and Yamamoto, Y., 2003. Men's Health Study. Circulation Journal 67 (8), pp. 656-59.

[12] Watts, G. F., Chew, K. K. and Stuckey, B. G. 2007. The erectile-endothelial dysfunction nexus: new opportunities for cardiovascular risk prevention. Nature Reviews Cardiology 4 (5), p. 263. 
[13] Montorsi, P., Ravagnani, P. M., Galli, S., Salonia, A., Briganti, A., Werba, J. P. and Montorsi, F., 2006. Association between erectile dysfunction and coronary artery disease: matching the right target with the right test in the right patient. European Urology, 50 (4), pp. 721-31.

[14] Burchardt, M., Burchardt, T., Baer, L., Kiss, A. J., Pawar, R. V., Shabsigh, A., De La Taille, A., Hayek, O. R. and Shabsigh, R., 2000. Hypertension is associated with severe erectile dysfunction. The Journal of Urology 164 (4), pp. 1188-91.

[15] Chun J, and Carson CC., 2001. Physician-patient dialogue and clinical evaluation of erectile dysfunction. Urologic Clinic of North America 28, pp. 249-58.

[16] Rosen, R. C., Cappelleri, J. C., Smith, M. D., Lipsky, J. and Pena, B. M., 1999. Development and evaluation of an abridged, 5-item version of the International Index of Erectile Function (IIEF-5) as a diagnostic tool for erectile dysfunction. International Journal of Impotence Research, 11 (6), pp. 31926.

[17] Burchardt, M., Burchardt, T., Anastasiadis, A. G., Kiss, A. J., Shabsigh, A., de La Taille, A., Pawar, R. V., Baer, L. and Shabsigh, R., 2001. Erectile dysfunction is a marker for cardiovascular complications and psychological functioning in men with hypertension. International journal of impotence research 13 (5), p. 276.

[18] Jensen, J., Lendorf, A., Stimpel, H., Frost, J., Ibsen, H. and Rosenkilde, P., 1999. The prevalence and etiology of impotence in 101 male hypertensive outpatients. American Journal of Hypertension, 12 (3), pp. 271-75.

[19] Mittawae, B., El-Nashaar, A. R., Fouda, A., Magdy, M. and Shamloul, R., 2006. Incidence of erectile dysfunction in 800 hypertensive patients: a multicenter Egyptian national study. Urology 67 (3), pp. 575-78.

[20] Korenman, S. G., 1998. New insights into erectile dysfunction: a practical approach. The American Journal of Medicine, 105 (2), pp. 135-44.

[21] Feldman, H. A., Goldstein, I., Hatzichristou, D. G., Krane, R. J. and McKinlay, J. B., 1994. Impotence and its medical and psychosocial correlates: results of the Massachusetts Male Aging Study. The Journal of Urology 151 (1), pp. 54-61.

[22] Prisant, L. M., Carr, A. A., Bottini, P. B., Solursh, D. S. and Solursh, L. P., 1994. Sexual dysfunction with antihypertensive drugs. Archives of Internal Medicine 154 (7), pp. 730-36.

[23] Grimm, R. H., Grandits, G. A., Prineas, R. J., McDonald, R. H., Lewis, C. E., Flack, J. M., et al 1997. Long-term effects on sexual function of five antihypertensive drugs and nutritional hygienic treatment in hypertensive men and women. Hypertension 29 (1), pp. 8-14.
[24] Kushiro, T., Takahashi, A., Saito, F., Otsuka, Y., Soma, M., Kurihara, T., Satomura, A., Saito, T. and Kanmatsuse, K., 2005. Erectile dysfunction and its influence on quality of life in patients with essential hypertension. American Journal of Hypertension 18 (3), pp. 427-30.

[25] Cao, S., Yin, X., Wang, Y., Zhou, H., Song, F. and Lu, Z., 2013. Smoking and risk of erectile dysfunction: systematic review of observational studies with meta-analysis. PLoS One 8 (4), p. e60443.

[26] Dorey, G., 2001. Is smoking a cause of erectile dysfunction? A literature review. British Journal of Nursing 10 (7), pp. 45565 .

[27] Feldman, H. A., Johannes, C. B., Derby, C. A., Kleinman, K. P., Mohr, B. A., Araujo, A. B. and McKinlay, J. B., 2000. Erectile dysfunction and coronary risk factors: prospective results from the Massachusetts male aging study. Preventive medicine 30 (4), pp. 328-38.

[28] Johannes, C. B., Araujo, A. B., Feldman, H. A., Derby, C. A., Kleinman, K. P. and McKinlay, J. B., 2000. Incidence of erectile dysfunction in men 40 to 69 years old: longitudinal results from the Massachusetts male aging study. The Journal of Urology 163 (2), pp. 460-63.

[29] Moreira Júnior, E. D., Bestane, W. J., Bartolo, E. B. and Fittipaldi, J. A. S., 2002. Prevalence and determinants of erectile dysfunction in Santos, southeastern Brazil. Sao Paulo Medical Journal 120 (2), pp. 49-54.

[30] Bacon, C. G., Mittleman, M. A., Kawachi, I., Giovannucci, E., Glasser, D. B. and Rimm, E. B., 2003. Sexual function in men older than 50 years of age: results from the health professional's follow-up study. Annals of Internal Medicine 139 (3), pp. 161-68

[31] Vallancien, G., Emberton, M., Harving, N. and van Moorselaar, R. J. A., 2003. Sexual dysfunction in 1,274 European men suffering from lower urinary tract symptoms. The Journal of Urology 169 (6), pp. 2257-61.

[32] Chung WS, Park YY, Kwon SW., 1997. The impact of aging on penile hemodynamics in normal responders to pharmacological injection: a doppler sonographic study. The Journal of Urology., 157 pp. 229-31.

[33] Derby, C. A., Mohr, B. A., Goldstein, I., Feldman, H. A., Johannes, C. B. and McKinlay, J. B., 2000. Modifiable risk factors and erectile dysfunction: can lifestyle changes modify risk. Urology 56 (2), pp. 302-6.

[34] Chitaley, K., Kupelian, V., Subak, L. and Wessells, H., 2009. Diabetes, obesity and erectile dysfunction: field overview and research priorities. The Journal of Urology 182 (6), pp. S45S50. 